\title{
PÓS-MODERNIDADES: BREVE \\ EXPLICITAÇÃO DA CRÍTICA DE DAVID \\ HARVEY A JEAN-FRANÇOIS LYOTARD
}

Josué Borges de Araújo Godinho*

\author{
* josuebagodinho@gmail.com \\ Doutorando em Teoria da Literatura e Literatura Comparada pelo \\ Programa de Pós-Graduação em Estudos Literários da Faculdade \\ de Letras da UFMG.
}

RESUMO: Este breve texto tenta explicitar a crítica feita por David Harvey, em Condição pós-moderna, a Jean-FrançoisLyotard. $\mathrm{O}$ trabalho leva em consideração as leituras que ambos fazem da chamada "pós-modernidade", tendo em mente, dentre outras coisas, a surpresa de Harvey diante do conceito de "justiça" apresentado por Lyotard e a problematização, por parte de Harvey, de um dos aspectos mais caros ao pós-modernismo, que é a intensa fragmentação da linguagem e do(s) sujeito(s) a partir dos anos de 1960 e 1970, além da questão da cumplicidade crescente entre o pós-modernismo e a estetizacão da política. $\mathrm{O}$ método de análise confronta os procedimentos de Harvey e Lyotard diante da pós-modernidade.

PALAVRAS-CHAVE: David Harvey, Jean-François Lyotard, pós-modernidade, fragmentação, narrativas.
RÉSUMÉ: Ce court texte tente d'expliquer la critique faite par David Harvey, dans Condição pós-moderna, a Jean-François Lyotard,. Le travail prend en compte les lectures qui font à la fois l'appel "post-moderne», en tenant compte, entre autres choses, la surprise de Harvey au concept de «justice», présenté par Lyotard et le questionnement, par Harvey, en effet la fragmentation intense qui survient surtout après 1970, au-delà de la question de la complicité grandissante entre postmodernisme et l'esthétique de la politique. La méthode d'analyse confronte les procédures pour Harvey et Lyotard en face de la postmodernité.

MOTS-CLÉS: David Harvey, Jean-François Lyotard, postmodernisme, fragmentation, récits. 
Gostaria de partir da hipótese de que a abordagem, que se pretenda consistente e coerente, do que se convencionou chamar o pós-modernismo ou a pós-modernidade, deva levar em consideração, em primeiro lugar, os pontos de intersecção entre esta dominante cultural e aquela que a precedeu, o modernismo, em seguida, o seu caráter predominantemente multifacetado e fragmentário, além de um aspecto fundamental, apontado por Jameson, que é a superficialidade. Quero dizer, com isto, que a abordagem deve ser necessariamente relacional, ou seja, deve ter em conta que os elementos predominantes da dominante cultural pós-moderna estão tão disseminados nos diferentes campos do conhecimento que sua análise teórico-crítica deve tê-los sempre em conta. E que a abordagem que faça um corte sistemático, não-relacional, pinçando apenas um de seus aspectos em detrimento dos demais, tende a não atingir a contento a dimensão do que possa ser chamado de pós-modernismo. Não pretendo, contudo, afirmar que a abordagem relacional dê uma visão completa da vertente cultural dominante, mas, convém dizer, permite ao interlocutor equacionar melhor o problema, ainda que de forma muitas vezes precária.

A seguir, tomemos em suas intersecções as abordagens de Lyotard e David Harvey sobre a "condição pós-moderna", bem como a crítica que este faz àquele.

A primeira crítica que David Harvey faz, em seu Condição Pós-moderna, à análise de Lyotard sobre o pós-modernismo é retirada de uma simplificação do próprio Lyotard. Para Harvey, "Lyotard define o pós-moderno simplesmente como "incredulidade diante das metanarrativas". ${ }^{1}$ Com efeito, tem-se a impressão de que Lyotard define sua análise nesses termos. Sinto-me tentado, então, a ver o seu livro como um portentoso metarrelato de legitimação da cultura pós-moderna. Quando se propõe ali é uma análise, pautada pelo desenvolvimento do conceito de pós-moderno, do processo de substituição/descrença dos grandes relatos pelos pequenos relatos, a substituição do consenso pelo dissenso ou paralogia, bem como a posição que ocupa o saber nas sociedades mais desenvolvidas, ou, para falar com Lyotard, nas sociedades pós-industriais.

É seguindo esse raciocínio que Lyotard pinça no pós-modernismo o seu aspecto lingüístico, ou o que ele vai chamar, tomando de empréstimo a Wittgenstein, de "jogos de linguagem”. O autor concentra seus esforços em analisar nesse novo contexto as transformações ocorridas nos "jogos da linguagem", ou nos relatos de legitimação do saber ou do conhecimento em seus aspectos de produção da cultura nas sociedades mais avançadas. Através da abordagem do elemento linguístico, Lyotard pretende problematizar a passagem da legitimação da verdade perseguida e estabelecida nas ciências tradicionais por meio da comprovação/argumentação por meio dos grandes relatos e do consenso entre as partes
1. HARVEY. Condição pós-moderna, p. 50.

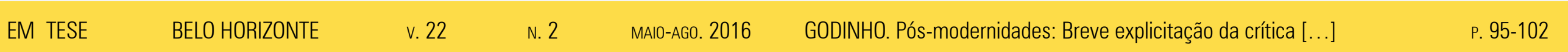


2. BARBOSA. Tempos pósmodernos, $\mathrm{p}$. xi.

3. LYOTARD. A condição pósmoderna, p. 53.

4. LYOTARD. A condição pósmoderna, p. 3-5. envolvidas no processo de legitimação. Segundo Wilmar do Valle Barbosa, em prefácio ao livro de Lyotard, "assistimos à rediscussão da noção de 'desordem”, a partir da consideração desse aspecto, aponta-se para a impossibilidade de submissão de "todos os discursos (ou jogos de linguagens) à autoridade de um metadiscurso que se pretende universal e consistente". ${ }^{2}$

É possível apontar, contudo, uma inconsistência nesse argumento de desautorização do metadiscurso, uma vez que Lyotard aponta constantemente para uma dominante tecnocrática que, em seus termos, parece reger o teor dos pequenos relatos, sobretudo no que tange às suas pretensões de melhor desempenho e maior poder. Mas isso não é tudo.

Cumpre ressaltar, conforme a crítica que Harvey faz de Lyotard, o fascínio de grande parte dos pensadores pós-modernos pelas "novas possibilidades da informação e da produção, análise e transferência do conhecimento". ${ }^{3} \mathrm{Na}$ esteira desse fascínio, Lyotard tem seu argumento firmemente fundamentado pela emergência das novas tecnologias. Alguns pontos de sua análise podem ser trazidos para a discussão por exemplo: 1. Propõe um trabalho com a mudança do estatuto do saber na sociedade pós-industrial; 2. Sendo um cenário "essencialmente cibernético-informático e informacional", as tecnologias da informação têm incidência direta sobre o saber; 3. Há um processo de exteriorização do saber que exclui o antigo princípio da formação; 4. O saber será produzido para ser vendido e consumido. ${ }^{4}$
Para Harvey ${ }^{5}$ é dentro desse contexto que Lyotard "examina de perto as novas tecnologias de produção, disseminação e uso desse conhecimento, considerando-as 'uma importante força de produção”. Harvey aponta nesses aspectos um problema, uma vez que, segundo Lyotard, dentro dessa "ordem" das coisas, todo o conhecimento pode ser codificado de maneiras diversas e tornado acessível. Isso tem implicações diretas com o quarto ponto do parágrafo anterior, ou seja, a codificação informatizada do conhecimento, que é, por sua vez, uma maneira de acumulação e disponibilização de saber e conhecimento com fins de ser vendido e consumido, ou, mais precisamente, para que tenha exatamente um valor de "troca" (e entenda-se a palavra em termos especialmente mercadológicos) e não de "uso".

Voltando à oposição proposta por Lyotard entre os metarrelatos e os pequenos relatos, as observações são importantes e merecem atenção. O pensador afirma que "a função narrativa" da linguagem "perde seus atores”, ou seja, "os grandes heróis, os grandes perigos, os grandes périplos e o grande objetivo". ${ }^{6}$ Perde, nesses termos, portanto, a busca da verdade, a legitimação de uma verdade, o seu caráter teleológico. Para Lyotard, os elementos das grandes narrativas estão dispersos "em nuvens de elementos de linguagens" (e qualquer semelhança com os dispositivos virtuais de arquivamento contemporâneos, chamados nuvens, não deve ser apenas coincidência) de ordem diversa. Nesse sentido, o
5. HARVEY. Condição pós-moderna, p.53.

6. LYOTARD. $A$ condição pósmoderna, p. xvi.

EM TESE BELO HORIZONTE $\quad$ v. $22 \quad$ N. 2 MAI0-AGo. 2016 GODINHO. Pós-modernidades: Breve explicitação da crítica [...] $\quad$ P. 95-102

\section{Teoria da literatura e Ensino de literatura}


7. LYOTARD. A condição pósmoderna, p. xvi.

8. HARVEY. Condição pós-moderna, p. 53-54. autor diz que vivemos em encruzilhadas de linguagens nas quais "não formamos combinações de linguagens necessariamente estáveis, e as propriedades destas por nós formadas não são necessariamente comunicáveis" .

Nesse ponto, Harvey chama a atenção para importante aspecto relativo à teoria da linguagem e da comunicação aceito pelos pós-modernistas. Para Harvey, ao passo que modernistas "pressupunham uma relação rígida e identificável entre o que era dito e o modo como estava sendo dito", os pós-modernistas enxergaram no pensamento pós-estruturalista, que vê esses elementos "separando-se e reunindo-se continuamente em novas combinações", um importante estímulo para seus modos de pensamento. ${ }^{8}$ Harvey aproxima aqui o pensamento pós-moderno ao desconstrucionismo dos anos 1960 e 1970, e nesta aproximação talvez resida um dos aspectos mais caros ao pós-modernismo, que é a fragmentação.

Nos pressupostos do desconstrucionismo, Harvey ressalta um "modo de pensar sobre textos e de 'ler' textos". Através desse modo, ficam evidentes não só a dissolução do sujeito pleno e do texto como um todo, de modo que o texto, o sujeito, o indivíduo, é visto na sua constante intersecção com outros textos; mais precisamente, Harvey diz que "escritores que criam textos ou usam palavras o fazem com base em todos os outros textos e palavras com que deparam, e os leitores lidam com eles do mesmo jeito". Isso leva à constatação de que a vida cultural pode ser vista "como uma série de textos em intersecção com outros textos". ${ }^{9}$

Tal entrecruzamento de textos, para falar ainda com Harvey, "tem vida própria”, e, nesses termos, podemos dizer que se constrói rizomaticamente, de forma tal que traz junto não só a dissolução do texto mesmo, como também a dissolução, ou, se preferirmos, para falar com Derrida, a disseminação e proliferação de sentidos não previamente planejados ou pretendidos, os quais escapam ao controle sobre o texto. De todo modo, escreve Harvey, os sentidos, os textos, estão "fora do nosso controle; a linguagem opera através de nós". ${ }^{10}$

Pensar nesses termos é considerar enormemente a fragmentação, ela mesma já existente no modernismo, mas com uma força incontrolável no pós-modernismo. Considerar o caráter fragmentário e multifacetado do pós-modernismo é caminhar numa via de pelo menos duas mãos de direção, para não dizer paradoxal. O pós-modernismo, escreve Harvey, endossando o pensamento de Huyssens, "tem especial valor por reconhecer 'as múltiplas formas de alteridade que emergem das diferenças de subjetividade, de gênero e de sexualidade, de raça, de classe, de (configurações de sensibilidade) temporal e de localizações e deslocamentos geográficos espaciais e temporais"'. ${ }^{11}$ Ao reconhecer tal multiplicidade, o pós-modernismo coloca na ordem do dia a diversidade, e a
9. HARVEY. Condição pós-moderna p. 54.

10. HARVEY. Condição pós-moderna, p. 54.

1. HARVEY. Condição pós moderna, p. 109.

EM TESE BELO HORIZONTE $\quad$ v. $22 \quad$ N. 2 MAIO-A60. 2016 GODINHO. Pós-modernidades: Breve explicitação da crítica [...] $\quad$ P. 95-102

\section{Teoria da literatura e Ensino de literatura}


12. HARVEY. Condição pósmoderna, p. 53.

13. HARVEY. Condição pósmoderna, p. 58.

14. HARVEY. Condição pósmoderna, p. 58. fragmentação, que o modernismo pretendia, senão mitigar, pelo menos unificar ou universalizar em função de um grande objetivo, de uma grande narrativa, de um grande telos.

Mas esse aspecto, por sua vez, pode ser visto como um problema, um complicador, não só pelo fato de ser temido pelos neoconservadores tradicionais. Mas, para Harvey, "aceitar a fragmentação, o pluralismo e a autenticidade de outras vozes e outros mundos traz o agudo problema da comunicação e dos meios de exercer o poder através do comando", ${ }^{12}$ uma vez que, no pós-modernismo, há "pouco esforço aberto para sustentar a continuidade de valores, de crenças ou mesmo de descrenças". ${ }^{13}$ Pode-se conjeturar, a partir dessa asserção, que no pós-modernismo, até mesmo a sua negação dos princípios modernos é insustentável, e, mesmo a aceitação da fragmentação, do plural e das vozes diversas, é, dentro de seu rizoma, transitório, fugidio, ou, para usar a metáfora anterior do desconstrucionismo, susceptível à dissolução.

Tais asserções dão a impressão de que há pouca seriedade no movimento pós-modernista. Sobretudo se seguimos à risca as críticas harveyanas a ele. Tal é o caso da afirmação de que este movimento "desenvolve uma capacidade de pilhar a história", de pegar "partes e pedaços do passado de maneira bem eclética" combinando-os e colando-os à vontade ${ }^{14}$ leva-nos a acreditar na construção de um imenso mosaico que visa congregar em si partículas diversas de diferentes tempos, lugares, alteridades, mas que, contudo, estão relacionados apenas superficialmente.

Isso leva-nos novamente à inegável tendência pós-moderna ao paradoxo. Se creditarmos confiança total á grande proposta de abertura às alteridades, às outras vozes, aos microrrelatos pretendidos pelo pós-modernismo, somos levados também a reconhecer nessa abertura um fechamento. Ao passo que a negação dos metarrelatos, das grandes narrativas universais abre espaço para os pequenos relatos, para micronarrativas, "circunscreve-as num gueto de alteridade opaca, de especificidade de um outro jogo de linguagem". ${ }^{15}$ Tais procedimentos privam de "poder essas vozes num mundo de relações de poder assimétricas". ${ }^{16}$

É nesse sentido que talvez seja-nos lícito apontar para uma primeira crítica que Harvey faz à tentativa de Lyotard de estabelecer um conceito de justiça. Se essas vozes estão circunscritas "num mundo de relações de poder assimétricas", convém creditar validade ao fato de que, nesse contexto, "a ação só pode ser concebida e decidida nos limites de algum determinismo local, de alguma comunidade interpretativa, e os seus sentidos tencionados e efeitos antecipados estão fadados a entrar em colapso quando retirados desses domínios isolados, mesmo quando coerentes com eles" ${ }^{17}$ Nesse ponto, Harvey chama a atenção para a afirmação de Lyotard, para
15. HARVEY. Condição pósmoderna, p. 112.

16. HARVEY. Condição pós moderna, p. 112.

EM TESE BELO HORIZONTE $\quad$ v. $22 \quad$ N. 2 MAIO-A60. 2016 GODINHO. Pós-modernidades: Breve explicitação da crítica [...] $\quad$ P. 95-102


18. LYOTARD apud HARVEY Condição pós-moderna, p. 56. quem "o consenso se tornou um valor suspeito e ultrapassado, mas a justiça como valor não é ultrapassada nem suspeita”. ${ }^{18}$ Há que se concordar que existe aí uma incongruência por parte da sentença de Lyotard, não só pela não explicação da permanência intocada da justiça num contexto em que tudo, inclusive o consenso, tenha-se tornado dissenso separação e relação assimétrica. A intocabilidade da justiça faz crer que ela tenha permanecido consensual, mesmo sendo o consenso um valor "suspeito e ultrapassado". Há certa conformidade, atrelada ao desejo de mudança, por parte de Lyotard em relação à justiça, uma vez que o pensador aponta para o desejo de disjungir a justiça da ideia de consenso. Não há, contudo, proposição ou caminho para tal.

E é a partir de tal asserção que chegamos a uma crítica tanto mais mordaz, não só aos pressupostos de Lyotard, mas também à retórica do pós-modernismo. Aqui, Harvey chama não só Jameson, mas também Eagleton. A citação é longa, porém, necessária:

A retórica do pós-modernismo é perigosa, já que evita o enfrentamento das realidades da economia política nas circunstâncias do poder global. A ingenuidade da "proposta radical" de Lyotard, de franquear o acesso a todos os bancos de dados como prólogo para uma reforma radical (como se todos fôssemos ter igual poder de aproveitar essa oportunidade), é instrutiva, porque indica que mesmo o mais resoluto dos pós-modernistas no final tem de decidir se faz algum gesto universalizante (como o apelo de Lyotard a algum conceito prístico de justiça). Não é possível descartar a metateoria os pós-modernistas apenas a empurram para o subterrâneo, onde ela continua a funcionar como uma "efetividade agora inconsciente" (Jameson, 1984b). ${ }^{19}$

Torno ao princípio deste texto, quando manifestei a impressão de que o livro de Lyotard parecia ser um portentoso relato de legitimação da condição pós-moderna. Equacionar o problema em termos de sua "proposta radical", implica não só em, como afirma Jameson, "empurrar a metateoria para o subterrâneo”, mas em afirmar uma crença ilusória, através da multifacetada retórica pós-moderna, de acessibilidade ampla, por parte das alteridades, das múltiplas vozes, aos bancos de dados", quando o que vemos, ao contrário, é a já afirmada relação de poder assimétrica. Lyotard, nesses termos, se vale do recurso à metateoria, ao discurso legitimador e universalizante, ainda que aponte seu discurso para o dissenso, inscreve-o, pela retórica e pela argumentação, na ordem consensual.

Harvey se vê, enfim, em concordância com Eagleton, rejeitando os procedimentos retóricos do pós-modernismo e as ideias de Lyotard; para eles, nos termos deste último, "não pode haver diferença entre verdade, autoridade e sedução retórica; quem tem a língua mais macia ou a conversa mais
19. HARVEY. Condição pósmoderna, p. 112.

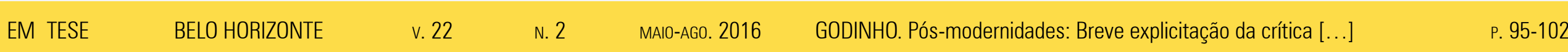


20. HARVEY. Condição pósmoderna, p. 112. moderna, p. 194. atraente tem o poder" ${ }^{20}$ E nesse ponto que a crítica tanto de Harvey quanto de Eagleton ao pós-modernismo e a Lyotard aproximam a retórica pós-moderna aos procedimentos de estetização da política.

A sentença de Lyotard legitima, ao seu modo, o procedimento de estetização da política, sobretudo no que diz respeito ao processo de legitimação do poder através do jogo da linguagem. Tem-se, nesses termos, não só uma detenção do poder por parte de quem é capaz de acumular e dominar melhor os jogos de linguagem, mas quem, no processo constante de "entrelaçamento intertextual", tem maior capacidade de "conversa mais atraente", dominando, de certo modo, os procedimentos lingüísticos, as intervenções possíveis, a autoridade e a autonomia sobre o saber e o conhecimento.

Harvey vê aí profundos problemas relativos à estetização da política, tanto por parte da esquerda quanto da direita. Para o pensador, ela tem implicações diretas com os "conflitos geográficos entre diferentes espaços na economia mundial”, bem como com a não gratuidade do caráter destrutivo desses conflitos geopolíticos. ${ }^{21}$ Harvey aponta como essencial a consideração da estetização da política para legitimação de tais conflitos, bem como concorda ele com a virada geopolítica capitalista, que assume "configurações de desenvolvimento desigual, fazendo-o buscar uma série de remédios espaciais para o problema da superacumulação".22
O pensador vê uma relação muito próxima entre a "conjunção de perspectivas teóricas estéticas e sociais sobre a natureza do espaço e do tempo". 23

É nesse sentido que podemos ver nas ideias de Lyotard um discurso de legitimação também da estetização da política, afirma este que "quem tem a língua mais macia ou a conversa mais atraente tem o poder". Ou seja, aquele que tem maior domínio sobre as teorias estéticas e maior capacidade de intervenção no espaço e no tempo, tem mais poder. E é a essa natureza de ideias que Eagleton, trazido à cena por Harvey, critica acidamente em Lyotard, que, afirma o teórico, ignora "o fato de os campos de morte terem sido, entre outras coisas, o rebento de um bárbaro irracionalismo que, tal como alguns aspectos do próprio pós-modernismo, desdenhava a história, recusava a argumentação, estetizava a política e atribuía tudo ao carisma aqueles que contavam as histórias". ${ }^{24}$

Ao fim, mas não ao cabo, havemos de concordar ainda com Harvey, para quem o "pós-modernismo vê a si mesmo de modo bem mais simples: na maioria das vezes, como um movimento determinado e deveras caótico voltado para resolver todos os supostos males do modernismo". ${ }^{25}$ Mas a tendência, por sua vez, está propensa a simplificar demais, não resolvendo os supostos males do modernismo, mas, talvez, exagerando-os, se consideramos "males" o fragmentário, o efêmero e o caótico. Tende à superfície, à estrutura
23. HARVEY. Condição pósmoderna, p. 194.

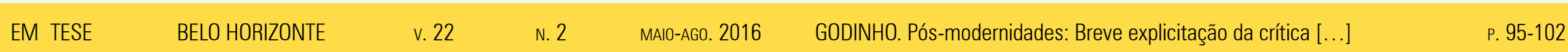

\section{Teoria da literatura e Ensino de literatura}


paratática que congrega em si toda a multiplicidade em existências simultâneas, mas jamais conectadas ou aprofundadas. E estes elementos de negação da profundidade e afirmação da superficialidade, para finalizar, são todos "aspectos vitais da prática artística na condição pós-moderna”.

\section{REFERÊNCIAS}

BARBOSA, Wilmar do Valle. Tempos pós-modernos. In.:

LYOTARD, Jean-François A condição pós-moderna. 9. ed. Trad. Ricardo Corrêa Barbosa. Rio de Janeiro: José Olympio, 2006. p. vii-xiii.

EAGLETON, Terry. Awekening from modernity. Times Literary Suplement, 20 Feb. 1987.

HARVEY, David Condição pós-moderna: uma pesquisa sobre as origens da mudança cultural. 24.ed. Trad. Adail Ubirajara Sobral e Maria Stela Gonçalves. São Paulo: Edições Loyola, 2013.

JAMESON, Fredric. Pós-modernismo: a lógica cultural do capitalismo tardio. Trad. Maria Elisa Cevasco. São Paulo: Ática, 1996.

LYOTARD, Jean-François. A condição pós-moderna 9 ed. Trad. Ricardo Corrêa Barbosa. Rio de Janeiro: José Olympio, 2006. 